\title{
An Experimental Study of Vegetable Solar Drying Systems with and without Auxiliary Heat
}

\author{
Abdul Jabbar N. Khalifa, ${ }^{1}$ Amer M. Al-Dabagh, ${ }^{2}$ and W. M. Al-Mehemdi² \\ ${ }^{1}$ College of Engineering, Nahrain University, P.O. Box 64040, Jadiriya, Baghdad, Iraq \\ ${ }^{2}$ Department of Mechanical Engineering, University of Technology, Baghdad, Iraq \\ Correspondence should be addressed to Abdul Jabbar N. Khalifa, ajkhalifa2000@yahoo.com
}

Received 13 April 2012; Accepted 6 June 2012

Academic Editors: S. Li, R. P. Saini, and S. Salter

Copyright ( 2012 Abdul Jabbar N. Khalifa et al. This is an open access article distributed under the Creative Commons Attribution License, which permits unrestricted use, distribution, and reproduction in any medium, provided the original work is properly cited.

\begin{abstract}
An experimental study is conducted to investigate the performance of a solely solar drying system and a system equipped with an auxiliary heater as a supplement to the solar heat. The performances of both are compared to that of natural drying. Beans and peas are dehydrated in a system that consists of two flat plate collectors, a blower, and a drying chamber. Tests with four different airflow rates, namely, $0.0383,0.05104,0.0638$, and $0.07655 \mathrm{~m}^{3} / \mathrm{s}$ are conducted. It was found that the drying time was reduced from 56 hours for natural drying to 12-14 hours for solar drying and to 8-9 hours for mixed (solar and auxiliary) drying. The efficiency of the mixed drying system was found to increase by $25 \%$ to $40 \%$ compared to the solely solar drying. A best fit to the experimental data of peas and beans was obtained by six exponential equations for the various systems with a correlation coefficient in the range 0.933 and 0.997 .
\end{abstract}

\section{Introduction}

Using the sun to dry crops and grains is one of the oldest, simplest, and least expensive ways of drying. Natural drying does not involve any cost but it is of many disadvantages such as long drying time during which the dried material is exposed to contamination and intrusion of insects and rodent leaving low quality dried material. Solar driers are used to lessen drying time and improve-the quality of product. The solar may be supplemented by auxiliary heat of different types to lessen further the drying time. It is often desirable to vary airflow rate through the system during the different stages of drying. Many types of auxiliary heat were used in the literature as a supplement. O'Donoghue and Fuller [1] used a $40-\mathrm{W}$ variable speed fan powered by a Photo Voltaic unit to deliver 0.139 to $0.055 \mathrm{~m}^{3} / \mathrm{s}$ of air to a tunnel dryer to dehydrate herbs and tomatoes using supplementary heat in the form of electricity and hot water. A structure of a dryer using solar energy and heat of geothermal water from a natural field for heating the dryer air was developed by Ivanova and Andonov [2]. A heat pump dryer was designed by Ceytan et al. [3] which was experimentally tested in drying tropical fruits such as kiwi, avocado, and banana. Eltief et al.
[4] used a solar assisted drying system consisted of drying chamber, V-groove collectors of, an auxiliary electric heater, and two variable speed centrifugal fans. Zomorodian et al. [5] introduced a rig consisted of six ordinary solar air heaters, an auxiliary electric heating channel, a drying chamber with an electrically rotary discharging valve and an air distributing system for paddy drying. Al-Juamily et al. [6] used a drying cabinet that had a transparent wall on its south side to enhance solar absorption in a system consisted of two solar collectors and an air blower to dry grapes, apricots, and beans. Bennamoun and Belhamri [7] used a heater during periods of low sunshine to dry onion.

The objective of this work is to investigate the benefit, over natural drying, of using solar drying with and without auxiliary heat for drying beans and peas under different airflow rates. Developing correlations that show the relation between the moisture content, flow rate, and drying time for the two systems is also an objective of this investigation.

\section{Approach}

The drying of materials involves migration of water from the interior of the material to its surface, followed by removal 
of water from the surface, which requires an amount of heat equals to the latent heat of evaporation of water. In most cases, the heat comes from the air, which is heated by the solar air collectors in the case of solar drying. Such equilibrium can be presented by the following equation:

$$
m_{w} h_{\mathrm{fg}}=m_{a} C_{p}\left(T_{\mathrm{oc}}-T_{\mathrm{ic}}\right) .
$$

The collector should deliver a quantity of heat which equals to

$$
Q=\operatorname{HR}(\overline{\tau \alpha}) t A_{C} \eta_{C} .
$$

The values of $m_{a}$ and $A_{C}$ are selected to accomplish the required drying conditions. The quantity of moisture evaporated from the dried material may be calculated from the following relation

$$
m_{w}=\frac{m_{i}\left(M_{i}-M_{f}\right)}{\left(1-M_{f}\right)} .
$$

The efficiency of the air collector may be calculated from the following relation

$$
\eta_{C}=\frac{Q_{u}}{\mathrm{HR} \cdot A_{C}} .
$$

The following relation shows the efficiency of the drying cabinet:

$$
\eta_{d}=\frac{P \cdot h_{\mathrm{fg}}}{\left(\mathrm{HR} \cdot A_{C}+W\right) t} .
$$

For the heater, the efficiency is calculated as follows:

$$
\eta_{h}=\frac{\dot{m} \cdot C_{p} \cdot \Delta T}{I \cdot V} .
$$

The efficiency of the drying system is calculated by multiplying the efficiencies of the individual components of the system.

\section{Experimental Setup and Test Procedure}

Two identical double-pass air collectors were constructed. The absorber was made from a $60^{\circ} \mathrm{V}$-groove galvanized steel sheet 1 -mm-thick with dimensions of $1.7 \times 0.7 \mathrm{~m}$. Matt black paint was used on the corrugated absorber to increase the absorptivity to solar radiation. A rock wool sheet was used to insulate the back and sides of the collector, which had final dimensions of $1.9 \times 0.9 \mathrm{~m}$ as shown in Figure 1. The collectors were oriented due south at a tilt angle of $45^{\circ}$. More details on the performance of the air collectors may be found in AlJuamily et al. [6].

A 1000-W auxiliary heater was constructed from a galvanized steel sheet with a square cross sectional area that had a side length of $0.25 \mathrm{~m}$ as shown in Figure 2. A Heating filament was wrapped on ceramic isolators to provide the heat. The heater was insulated from the inside by a $5-\mathrm{mm}$ thick asbestos sheet and from the outside by a 20 -mm-thick aluminum-coated rock wool sheet to minimize heat loss. A

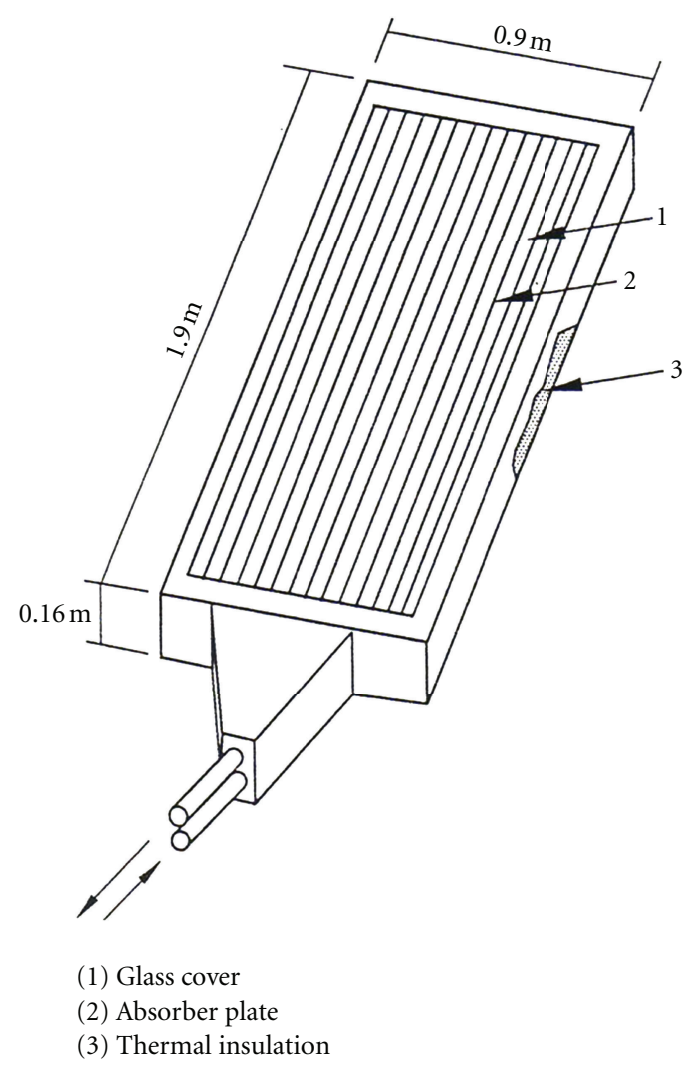

FIgURE 1: The details and dimensions of the double-pass air collector.

variac (type Zenith, range: $0-270 \mathrm{~V}$ ) was used to control the output power required to provide the selected inlet air temperature to the drying chamber. The power is calculated from the reading of the voltage provided by the variac and the amperage read by a digital multimeter (type ID-1000, range: $0-30 \mathrm{~A}$ and accuracy $\pm 0.75 \%$ ).

An aluminum drying chamber, which had the dimension of $1 \times 0.5 \times 0.8 \mathrm{~m}$ (length $\times$ width $\times$ height $)$ was insulated from the outside by a $30-\mathrm{mm}$ aluminum-coated rock wool sheet as shown in Figure 3. Two screened drying trays were used to hold the product. Hot air was delivered to the chamber throughout two 63-mm-diameter side holes, one under each shelf. Insulated plastic pipes $60-\mathrm{mm}$-diameter was used to connect the different parts of the system. A 370-W air blower was used to deliver the heated air to the system. Several tests were carried out on the systems using different airflow rates, namely, $0.0383,0.05104,0.0638$, and $0.07655 \mathrm{~m}^{3} / \mathrm{s}$. The quantity of air was controlled by a manual valve and its velocity was measured by a calibrated digital hotwire anemometer (type KANE-4000). A schematic diagram of the complete system is shown in Figure 4.

Calibrated thermocouple wires of type $\mathrm{T}$ (Copperconstantan) were connected to a microprocessor thermometer (type 6400, range: $-100-400^{\circ} \mathrm{C}$ and accuracy $\pm 1 \%$ ) to measure the temperatures in one-hour intervals. The measurements included the collector inlet and outlet temperatures, absorber plate temperature at six locations, interior 


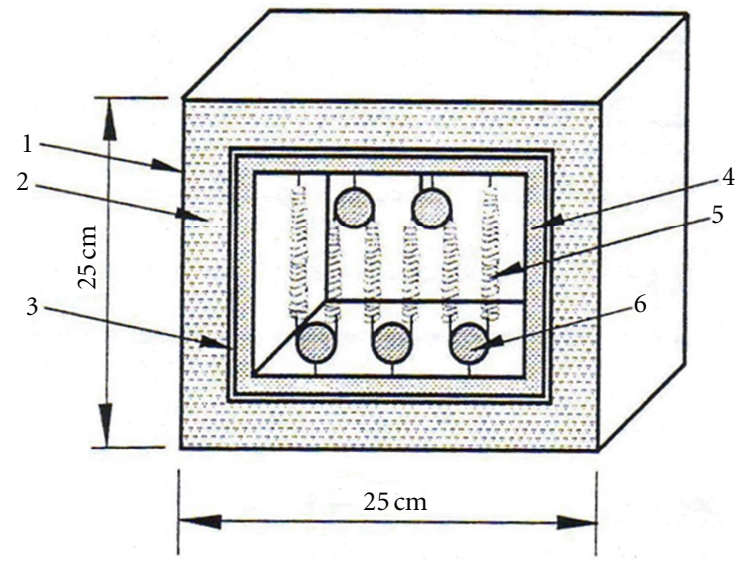
(1) Aluminum foil coating
(2) Thermal insulation
(4) Asbestos sheet
(3) Galvanized steel sheet
Heater filament
(6) Ceramic insulator

FIgure 2: The details of the auxiliary heater used in the drying system.

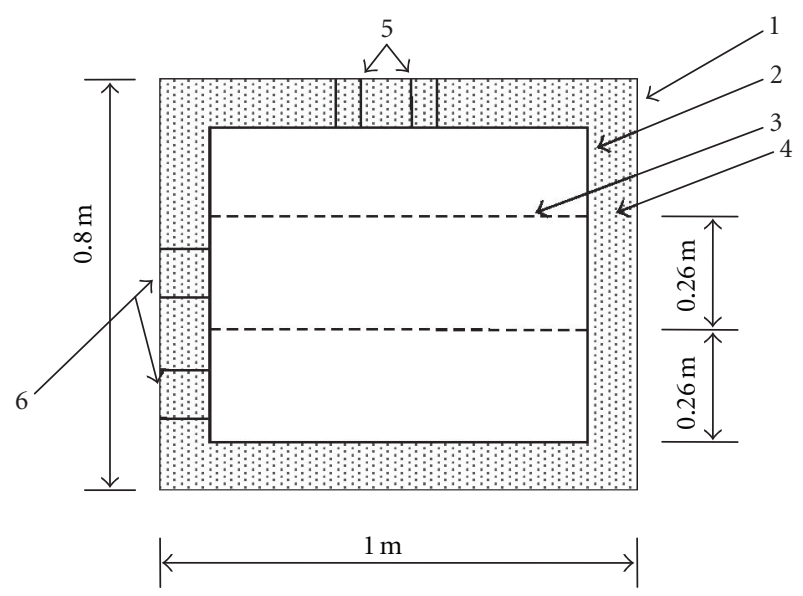
(1) Exterior aluminum plate
(4) Rock wool insulation
(2) Interior aluminum plate
(5) Vents
(3) Screened drying tray
(6) Hot air inlets

FIGURE 3: Schematic diagram of the drying chamber.

and exterior glass cover temperature, drying cabinet inlet and outlet temperatures, and the heater inlet and outlet temperatures (when applicable). The relative humidity of air was measured at the collector inlet and at the inlet and outlet of the drying chamber using a hygrometer (type HI-8064, range; $10-95 \%$ and accuracy $\pm 5 \%$ ). An in-site automatic meteorological station provided the hourly values of the ambient temperature and the global solar insolation on the plane of the collector using a PSP Eppley Pyranometer.

Equal quantities of product were used in natural, solar, and mixed drying as shown in Table 1. In natural drying, the product was left in the open air to dry. For the solar and mixed drying, the product was distributed evenly on the two shelves of the drying chamber. A sample of the dried material was taken and weighed every hour to calculate the moisture content. The sample was heated in an oven at a constant temperature for 48 hours until it becomes completely dry, the same balance was used to measure the weight of the dried sample. The weight of the sample was measured using a digital electronic balance (type PE-3600, range 0-500 g and accuracy $\pm 1.5 \%)$. The moisture content is calculated from the following relation:

$$
M=\frac{w_{s}-w_{d}}{w_{s}} \cdot 100
$$

\section{The Developed Correlations for the Drying Systems}

Empirical correlations for the solar and mixed drying systems for peas and beans were developed from the experimental data. The relation between the moisture content, drying time and the airflow rate for forced convection drying is given by the following form in ASHRAE Handbook of Fundamentals:

$$
M=a e^{-\left(b t_{d}+c \dot{Q}\right)} .
$$

Table 2 shows the correlations that obtained and the $R$ squared value for each correlation, which ranged from 0.986 and 0.997 . The correlations may be used to estimate one parameter (e.g., drying time) by knowing the other two parameters (i.e., airflow rate and the moisture content in this case) for peas and beans under airflow rate in the range 0.0383 and $0.07655 \mathrm{~m}^{3} / \mathrm{s}$.

More general and simpler correlations for the solar and mixed drying may be developed from the data of both peas and beans for all the airflow rates investigated in this study. Such correlations may be justified by the small effect of the airflow rate on the drying rate (Figures 5 and 6) and the small difference between the drying time of peas and beans (Table 1). The correlation developed for the solar drying of peas and beans is

$$
M=2296 e^{-0.35 t_{d}}, \quad R^{2}=0.949 .
$$

The one developed for the mixed drying for the two products is

$$
M=521.9 e^{-0.20 t_{d}}, \quad R^{2}=0.933 .
$$

Equations (9) and (10) are valid for airflow rates in the range 0.0383 and $0.7655 \mathrm{~m}^{3} / \mathrm{s}$.

\section{Results and Discussion}

Figures 5 and 6 show the time variation of moisture content for different airflow rates for solar and mixed drying for peas and beans, respectively, in comparison to natural drying. The advantage of the solar and mixed drying over the natural drying is obvious from the figures. Further, faster drying rate can be noticed for mixed drying in comparison to solar drying. It is interesting to note that the effect of changing the airflow rate on the drying time is more noticeable in solar drying than in mixed drying. 


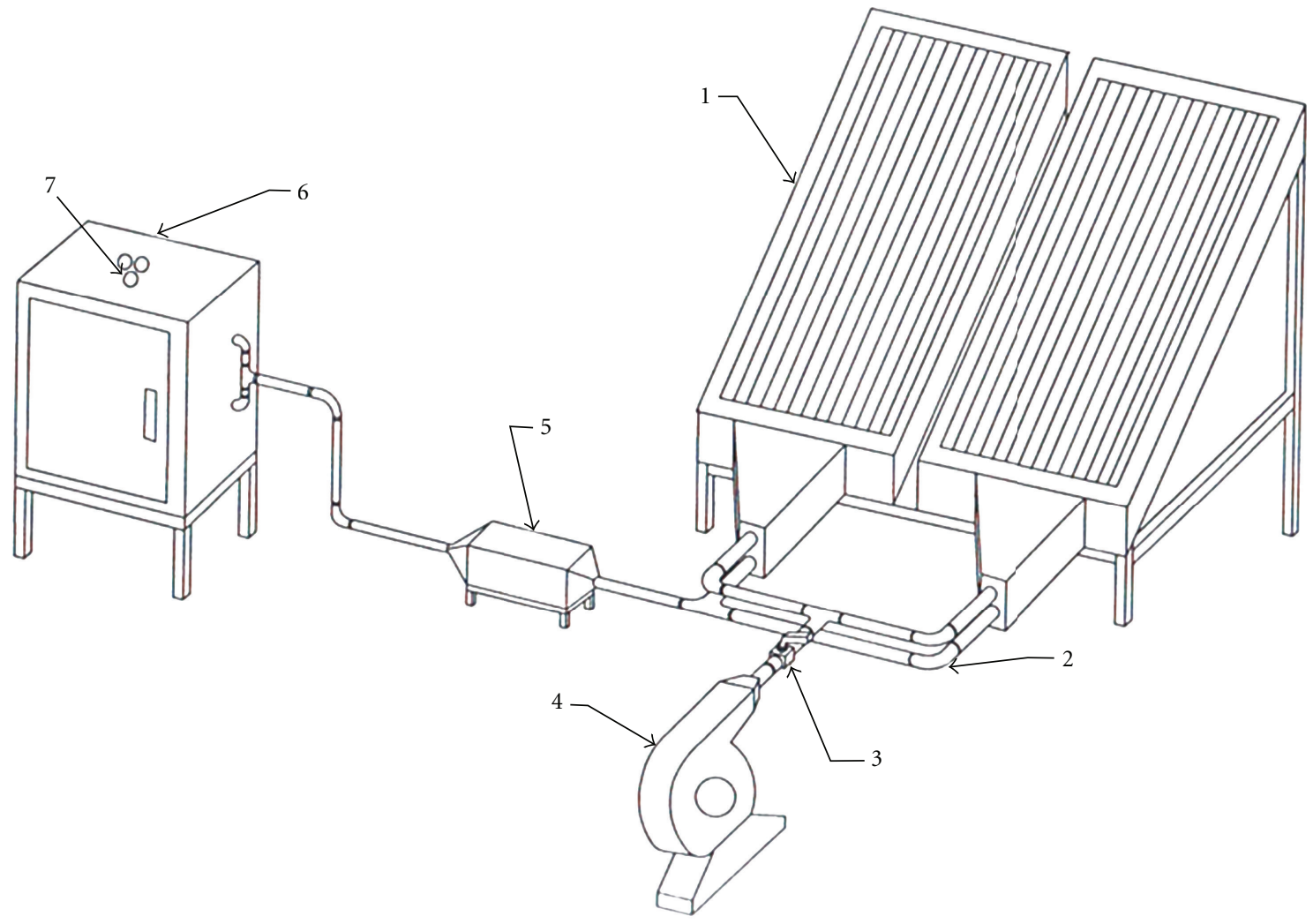
(1) Solar collector
(5) Auxiliary heater
(2) Connecting pipes
(3) Air valve
(6) Drying cabinet
(4) Air blower
(7) Vents

FIgURE 4: A schematic diagram of the drying system.

TABLE 1: The experimental results for mixed, solar, and natural drying for peas and beans.

\begin{tabular}{|c|c|c|c|c|c|c|c|}
\hline Material & $\begin{array}{c}\text { Weight } \\
\text { of product }(\mathrm{kg})\end{array}$ & $\begin{array}{c}\text { Type of } \\
\text { drying system }\end{array}$ & $\begin{array}{c}\text { Initial moisture } \\
\text { Content } \%\end{array}$ & $\begin{array}{c}\text { Final moisture } \\
\text { Content } \%\end{array}$ & $\begin{array}{c}\text { Required } \\
\text { volume of air }\left(\mathrm{m}^{3}\right)\end{array}$ & $\begin{array}{c}\text { Drying } \\
\text { time (hour) }\end{array}$ & $\begin{array}{l}\text { Energy delivered to } \\
\text { drying chamber (MJ) }\end{array}$ \\
\hline Peas & 10 & Mixed & 71 & 5 & 238 & 8 & 76.3 \\
\hline Peas & 10 & Solar & 71 & 5 & 655 & 12 & 62.7 \\
\hline Peas & 10 & Natural & 71 & 5 & - & 56 & - \\
\hline Beans & 8 & Mixed & 64.5 & 5 & 161 & 9 & 95 \\
\hline Beans & 8 & Solar & 64.5 & 5 & 471 & 14 & 73.2 \\
\hline Beans & 8 & Natural & 64.5 & 5 & - & 56 & - \\
\hline
\end{tabular}

TABLE 2: The empirical correlations for the solar and mixed drying systems for peas and beans.

\begin{tabular}{lccccc}
\hline \multirow{2}{*}{ Product } & \multirow{2}{*}{ Type of drying } & \multicolumn{4}{c}{$M=a e^{-\left(b t_{d}+c Q\right)}$} \\
& & $a$ & $b$ & $c$ & $R^{2}$ \\
\hline Peas & Mixed & 82.06 & 0.3622 & 1.960 & 0.993 \\
Peas & Solar & 87.05 & 0.2324 & 3.182 & 0.992 \\
\hline Beans & Mixed & 75.55 & 0.3641 & 2.623 & 0.997 \\
Beans & solar & 79.96 & 0.1918 & 3.557 & 0.986 \\
\hline
\end{tabular}

Figures $7,8,9$, and 10 show the time variation of the input power to the drying chamber and the moisture content of the dried material for the solar and mixed drying for air flow rates of $0.07655,0.0638,0.05104$, and $0.0383 \mathrm{~m}^{3} / \mathrm{s}$, respectively. A comparison between these figures shows an appreciable reduction in the input power for the two types of drying with the decrease in the flow rate accompanied by a slower reduction in moisture content of the dried material due to the lower energy input and smaller airflow rate.

Figure 11 shows the system efficiency for solar and mixed drying for different airflow rates. An increase of 25\% to $40 \%$ in the mixed drying system efficiency can be noticed. The range of efficiency is increased from 0.16 to 0.26 for the solely solar system to 0.20 to 0.35 for the auxiliary supplemented system. The time variation of the moisture content for mixed 


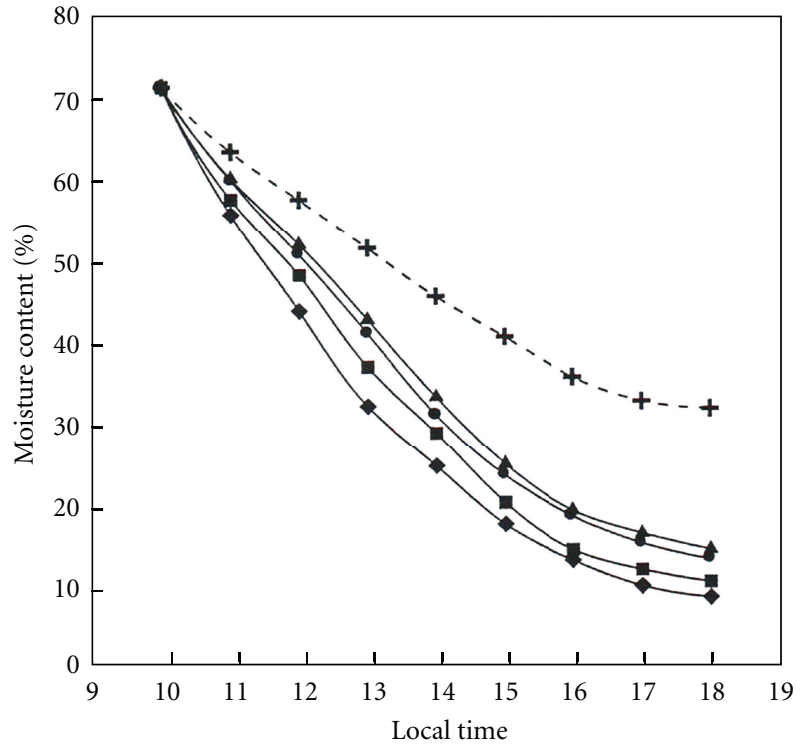

(a)

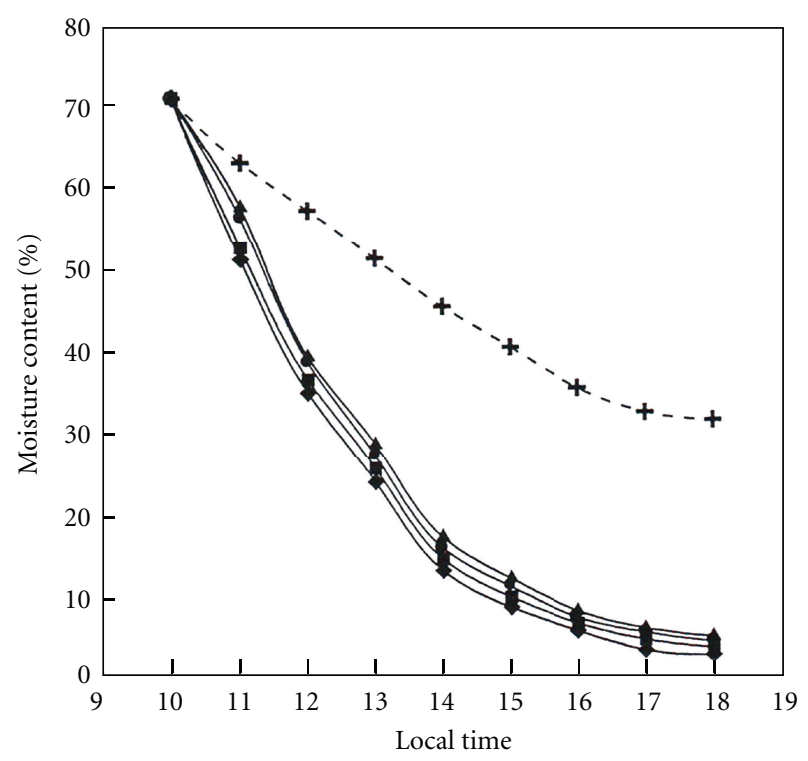

Solar drying

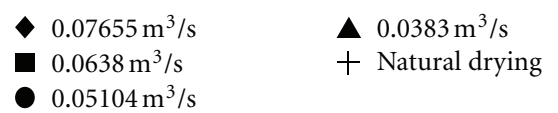

(b)

FIGURE 5: Time variation of moisture content for solar (a) and mixed drying (b) for peas with different flow rate.

and solar drying is shown in Figure 12 for different air flow rates and is compared to natural drying. The difference in drying time between the natural, solar and mixed drying is clear. Figure 13 shows the correlations of (9) and (10) that developed from the data of both peas and beans for all flow rates together with the average hourly values of the solar insolation for the days of the tests. Although the tests were carried out in different days, the average hourly solar insolation for the natural, solar and mixed drying tests show comparable valus as can be seen from the figure.

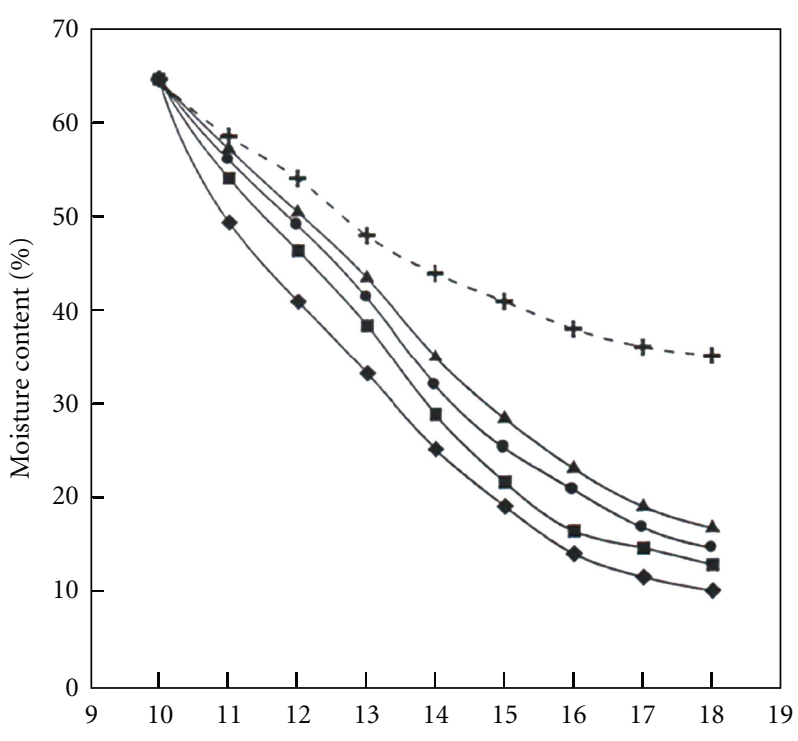

(a)

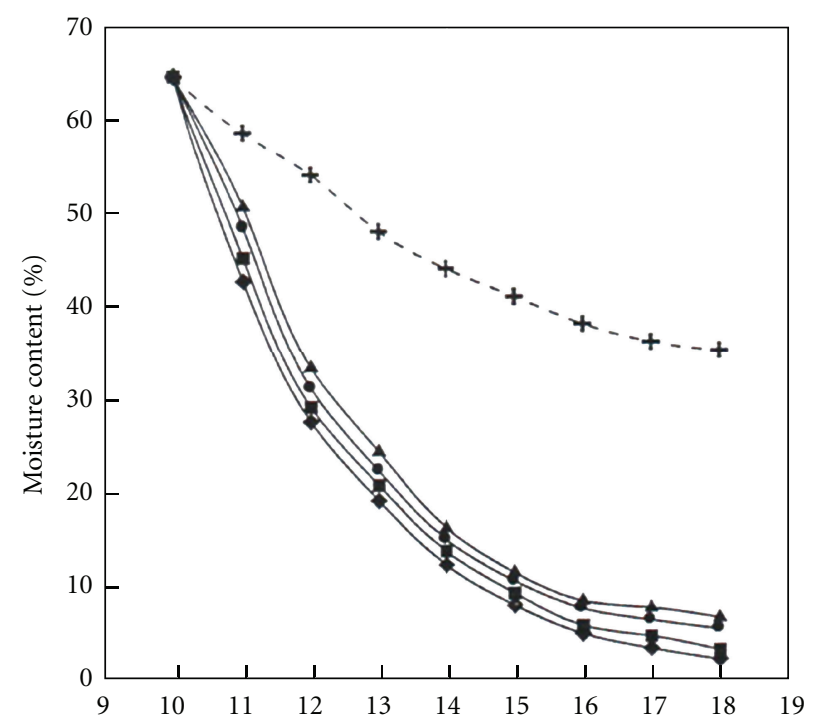

Solar drying

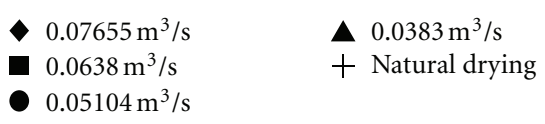

(b)

FIGURE 6: Time variation of moisture content for solar (a) and mixed drying (b) for beans with different flow rate.

Table 1 summerzies the results obtained for the tests on the two different products. The drying time is reduced from 56 hours for natural drying to 12-14 hours for solar drying and to 8-9 hours for mixed (solar plus auxiliary) drying. It can also be noticed that the quantity of air required for the mixed drying system $\left(238 \mathrm{~m}^{3}\right)$ is less than that for the solar drying system $\left(655 \mathrm{~m}^{3}\right)$. A reduction in the drying time by $33 \%$ and $36 \%$ for peas and beans respectively is obtained. This means less energy consumption by the air blower as well as shorter working hours. The energy required however is 


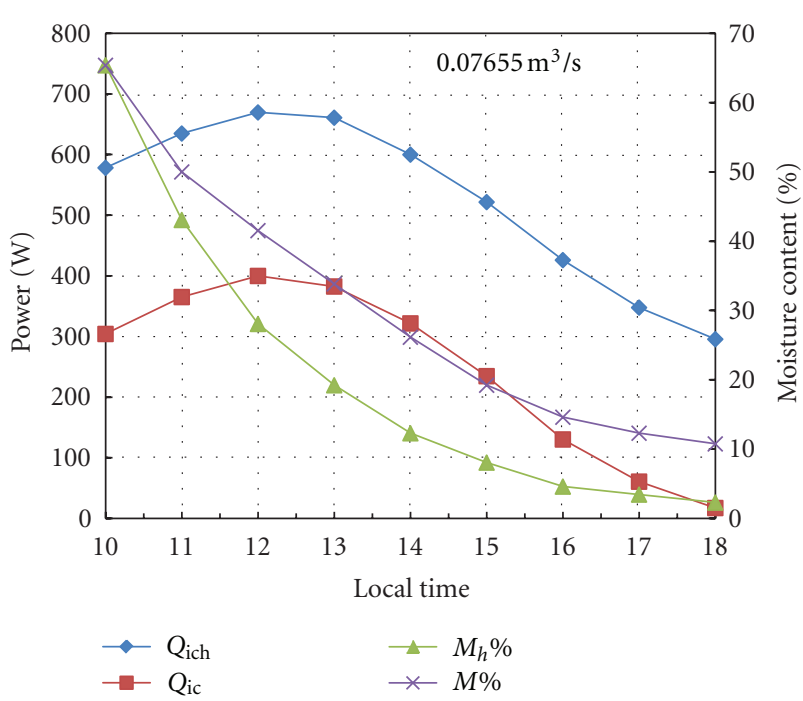

Figure 7: Time variation of input power to the drying chamber $\left(Q_{\text {ic }}, Q_{\text {ich }}\right)$ and the moisture content of the dried material $(M \%$, $M_{h} \%$ ) for solar and mixed drying, respectively, for an air flow rate of $0.07655 \mathrm{~m}^{3} / \mathrm{s}$.

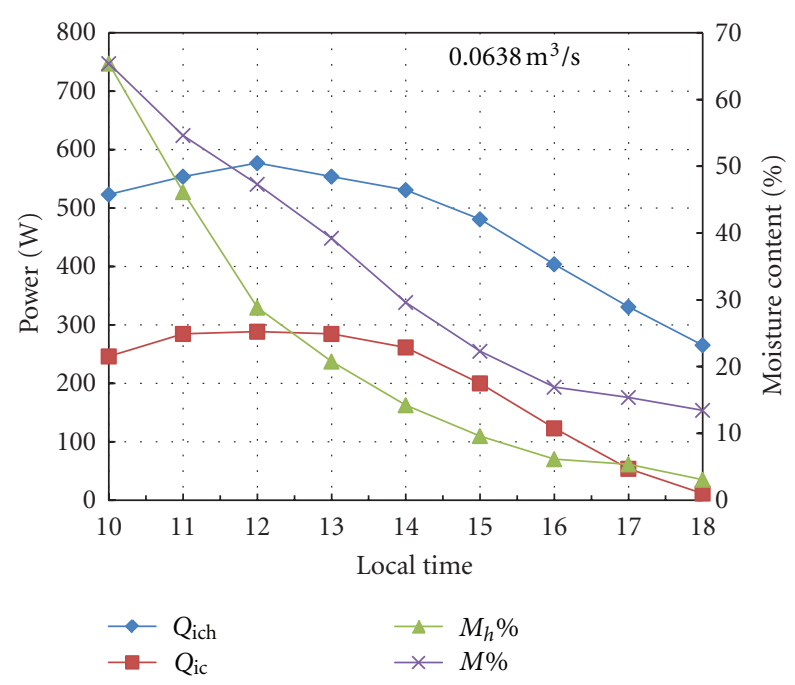

FIgURE 8: Time variation of input power to the drying chamber $\left(Q_{\text {ic }}, Q_{\text {ich }}\right)$ and the moisture content of the dried material $(M \%$, $\left.M_{h} \%\right)$ for solar and mixed drying, respectively, for an air flow rate of $0.0638 \mathrm{~m}^{3} / \mathrm{s}$.

increased by $22 \%$ for peas and by $30 \%$ for beans, which is the contribution of the auxiliary heater.

\section{Conclusions}

A solar drying system was investigated with and without auxiliary heater to evaluate the power, quantity of hot air, system efficiency and the time required for drying beans and peas under airflow rate in the range 0.0383 and

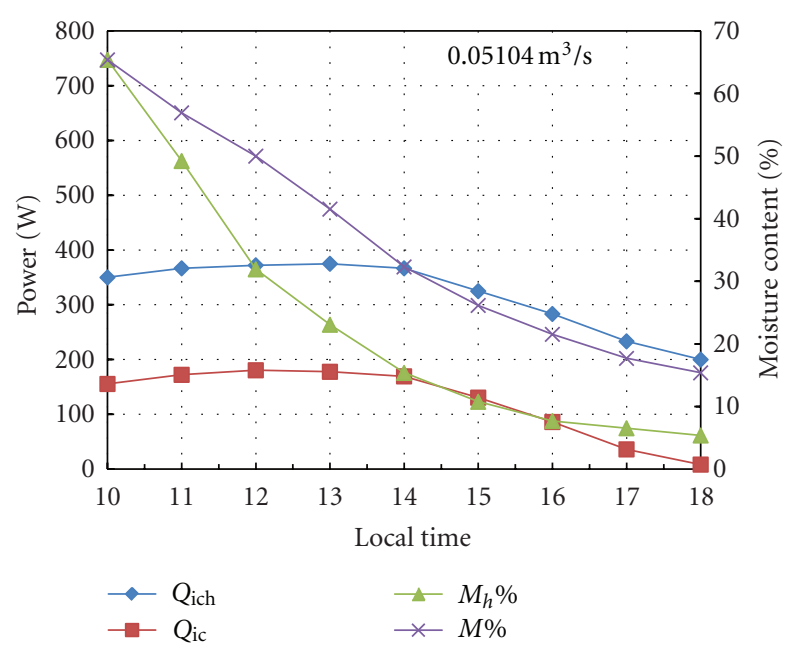

FIgURE 9: Time variation of input power to the drying chamber $\left(Q_{\text {ic }}, Q_{\text {ich }}\right)$ and the moisture content of the dried material $(M \%$, $M_{h} \%$ ) for solar and mixed drying, respectively, for an air flow rate of $0.05104 \mathrm{~m}^{3} / \mathrm{s}$.

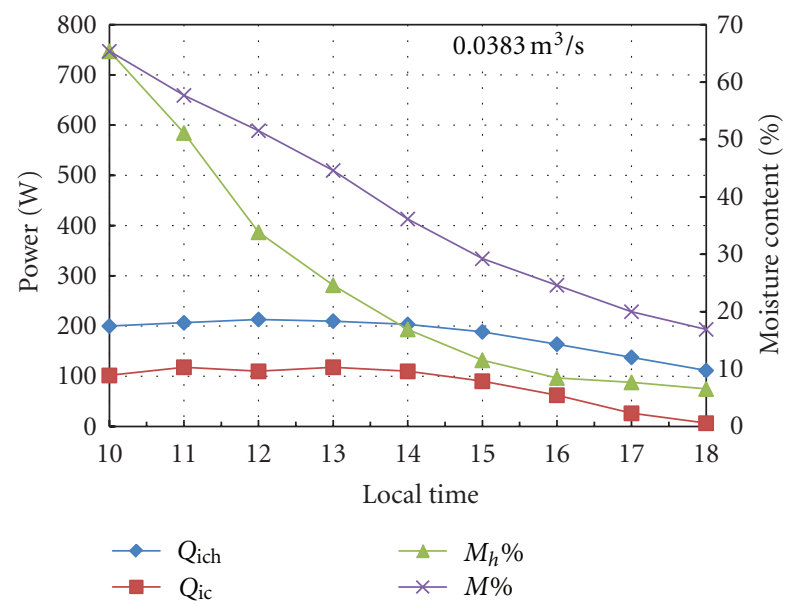

FIGURE 10: Time variation of input power to the drying chamber $\left(Q_{\text {ic }}, Q_{\text {ich }}\right)$ and the moisture content of the dried material $(M \%$, $M_{h} \%$ ) for solar and mixed drying, respectively, for an air flow rate of $0.0383 \mathrm{~m}^{3} / \mathrm{s}$.

$0.07655 \mathrm{~m}^{3} / \mathrm{s}$. The experimental investigation yielded the following conclusions:

(i) The drying time for both beans and peas was reduced from 56 hours for natural drying to 12-14 hours for solely solar drying and to 8-9 hours for mixed (solar plus auxiliary) drying.

(ii) An increase of $25 \%$ to $40 \%$ in the efficiency of the auxiliary supplemented drying system was found compared to that of the solely solar drying system.

(iii) The drying time was reduced by $33 \%$ and $36 \%$ for peas and beans respectively due to the use of the auxiliary heat accompained by increase in the energy required by $22 \%$ for peas and $30 \%$ for beans. 


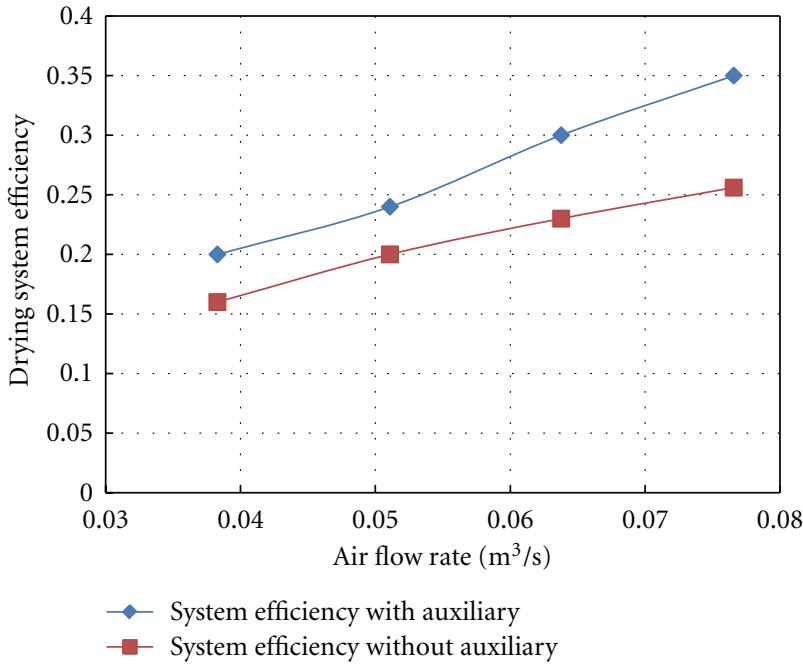

FIGURE 11: the variation of the solar system efficiency with and without auxiliary heat for different air flow rates.

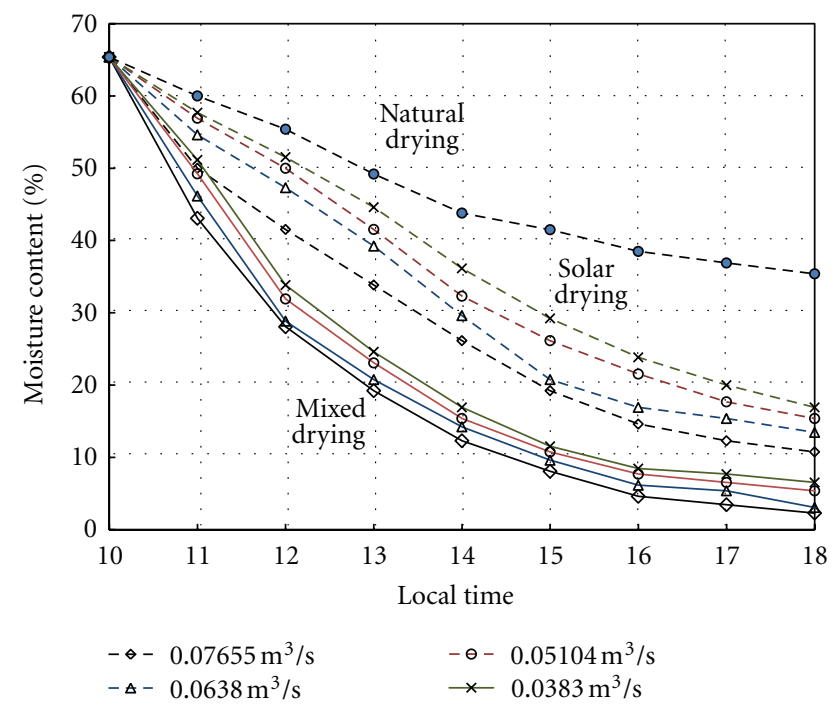

FIGURE 12: Time variation of moisture content of the dried material for mixed and solar drying for different air flow rates compared to that of natural drying.

(iv) A weak relation was observed between the variation of airflow rate and the decreaing rate of the moisture content of the dried material, especially for the mixed drying.

(v) The best fits of the drying of peas and beans were obtained by exponential equations which fitted the experimental data for the various systems with a correlation coefficients in the range 0.933 and 0.997 .

\section{Nomenclature}

$a, b, c$ : Empirical constants

$A_{C}: \quad$ Total collector area, $\mathrm{m}^{2}$

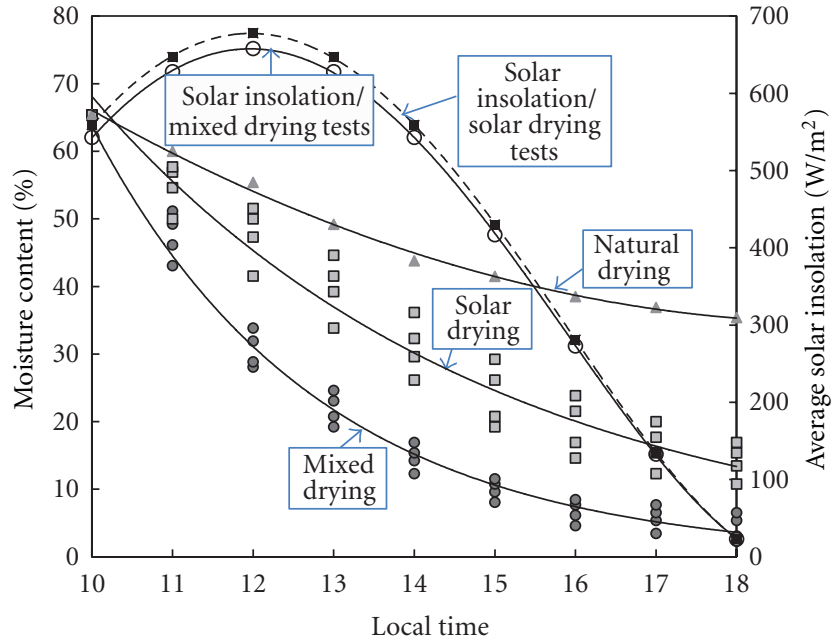

FIGURE 13: Time variation of moisture content of the dried material for mixed, solar, and natural drying and the average hourly solar insolation for the test dates.

$C_{p}$ : Specific heat of air, $\mathrm{J} / \mathrm{kg}^{\circ} \mathrm{C}$

$h_{\mathrm{fg}}$ : Latent heat of evaporation, $\mathrm{J} / \mathrm{kg}$

HR: Global solar radiation on the plane of the collector, $\mathrm{W} / \mathrm{m}^{2}$

I: $\quad$ Amperage, A

M: Moisture content of the dried material for solar drying, percentage

$m_{a}$ : Mass of air, $\mathrm{kg}$

$M_{f}:$ Final moisture content, $\mathrm{kg}$

$M_{h}$ : Moisture content of the dried material for mixed drying, percentage

$m_{i}: \quad$ Initial weight of dried material, $\mathrm{kg}$

$M_{i} \quad$ Initial moisture content, $\mathrm{kg}$

$m_{w}$ : Mass of water evaporated, $\mathrm{kg}$

$\dot{m}$ : Mass flow of air, $\mathrm{kg} / \mathrm{s}$

$P: \quad$ The productivity of the system, $\mathrm{kg}$

Q: Useful heat, J

$Q_{\mathrm{ic}}$ : Power input to the drying chamber for solar drying, $\mathrm{W}$

$Q_{\text {ich}}$ : Power input to the drying chamber for mixed drying, $\mathrm{W}$

$Q_{u}$ : The rate of useful energy gain by the collector, W

$\dot{Q}: \quad$ Airflow rate, $\mathrm{m}^{3} / \mathrm{s}$

$R^{2}: \quad R$-squared value for the correlation

$t$ : Time, $s$

$t_{d}: \quad$ Drying time, hour ((8) to (10))

$T_{\mathrm{ic}}$ : Inlet air temperature to the drying chamber, ${ }^{\circ} \mathrm{C}$

$T_{\mathrm{oc}}$ : Outlet air temperature from the drying chamber, ${ }^{\circ} \mathrm{C}$

$V: \quad$ Voltage, $\mathrm{V}$

$W$ : Auxiliary heater power, $\mathrm{W}$

$w_{d}$ : Weight of the sample after drying, $\mathrm{kg}$

$w_{s}$ : Weight of the sample before drying, $\mathrm{kg}$. 


\section{Greek Symbols}

$\alpha$ : $\quad$ Plate absorptance

$\Delta T:$ Temperature difference across the heater, ${ }^{\circ} \mathrm{C}$

$\eta_{C}:$ Collector efficiency, percentage

$\eta_{d}$ : Efficiency of drying cabinet, percentage

$\eta_{h}$ : Efficiency of heater, percentage

$\tau$ : $\quad$ Glass transmittance

$(\overline{\tau \alpha})$ : Effective transmittance-absorptance product.

\section{References}

[1] J. O’Donoghue and R. J. Fuller, "Experience with the Australian version of the Hohenheim solar tunnel dryer," in Proceedings of the 37th Annual Conference of the Australian and New Zealand Solar Energy Society (Solar '99), Victoria, Australia, 1999.

[2] D. Ivanova and K. Andonov, "Analytical and experimental study of combined fruit and vegetable dryer," Energy Conversion and Management, vol. 42, no. 8, pp. 975-983, 2001.

[3] I. Ceytan, M. Aktaş, and H. Doğan, "Mathematical modeling of drying characteristics of tropical fruits," Applied Thermal Engineering, vol. 27, no. 11-12, pp. 1931-1936, 2007.

[4] S. A. Eltief, M. H. Ruslan, and B. Yatim, "Drying chamber performance of V-groove forced convective solar dryer," Desalination, vol. 209, no. 1-3, pp. 151-155, 2007.

[5] A. Zomorodian, D. Zare, and H. Ghasemkhani, "Optimization and evaluation of a semi-continuous solar dryer for cereals (Rice, etc)," Desalination, vol. 209, no. 1-3, pp. 129-135, 2007.

[6] K. E. J. Al-Juamily, A. J. N. Khalifa, and T. A. Yassen, "Testing of the performance of a fruit and vegetable solar drying system in Iraq," Desalination, vol. 209, no. 1-3, pp. 163-170, 2007.

[7] L. Bennamoun and A. Belhamri, "Design and simulation of a solar dryer for agriculture products," Journal of Food Engineering, vol. 59, no. 2-3, pp. 259-266, 2003. 

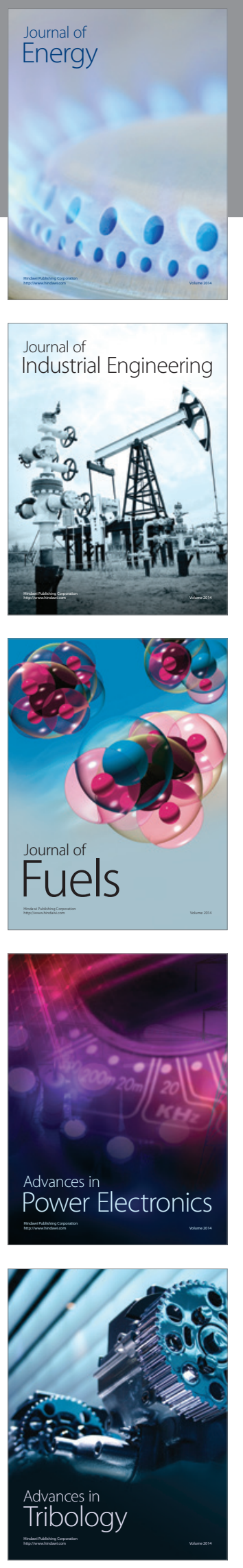
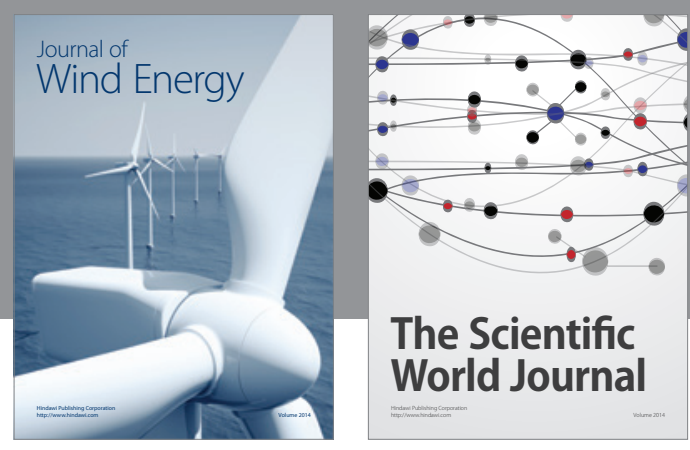

The Scientific World Journal

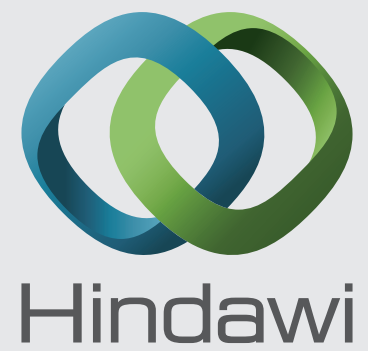

Submit your manuscripts at http://www.hindawi.com
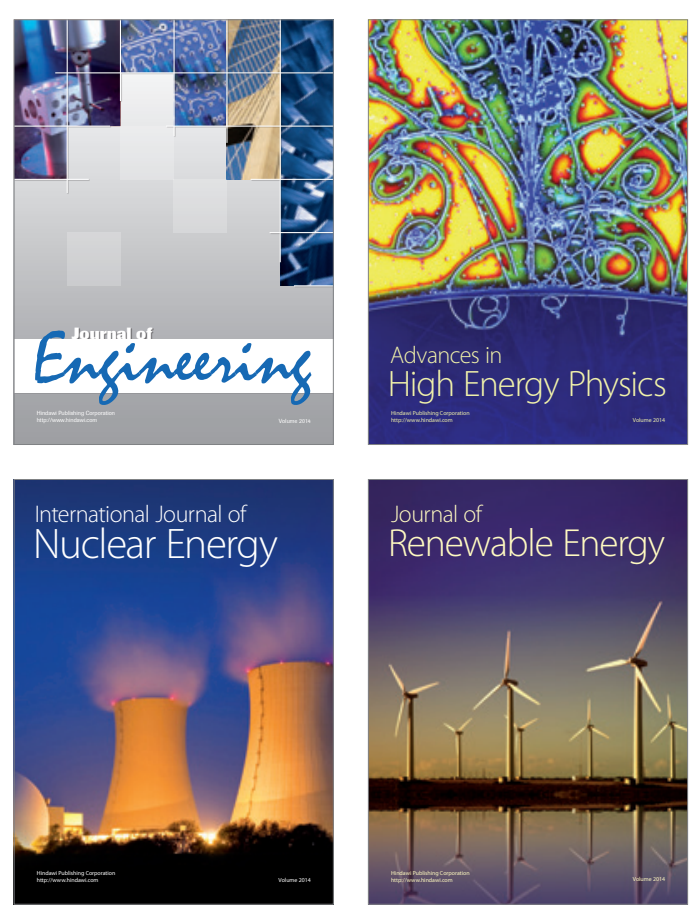

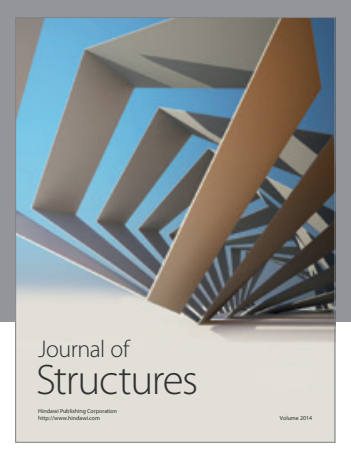

Rotating
Mechinery
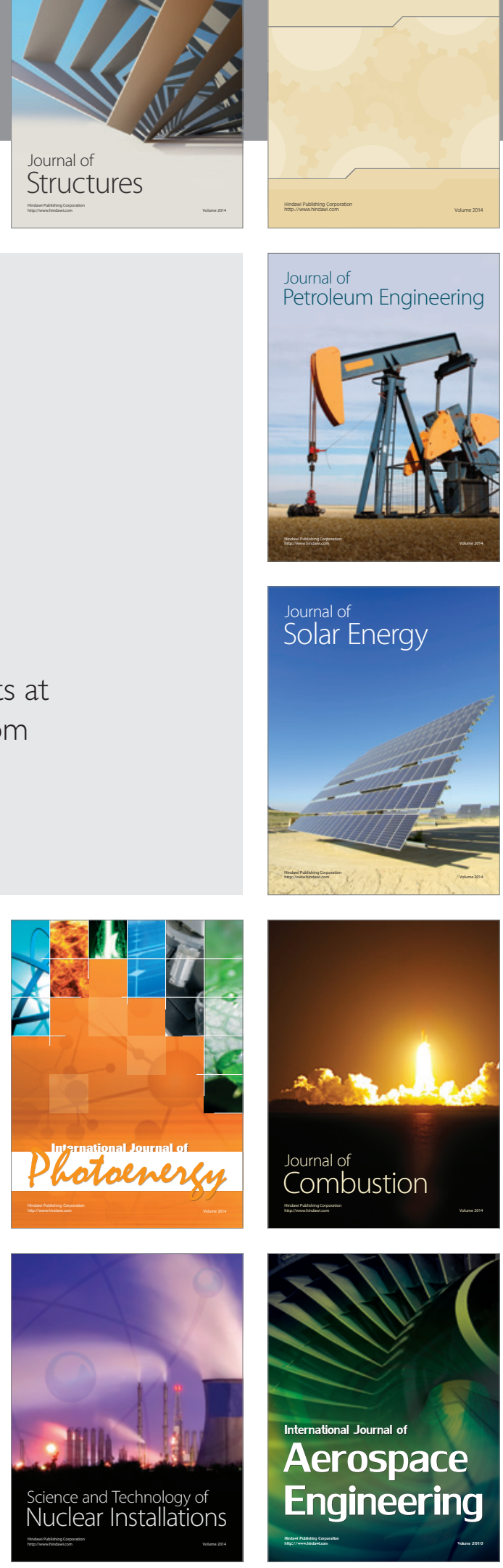